\title{
Costura líquida: uma história de enlaces e infiltrações
}

Liquid stitching: a story of bonds and infiltrations

Costura líquida: una historia de enlaces e infiltraciones 


\title{
Resumo
}

Este trabalho é um ensaio visual composto por oito desenhos da série nomeada Costura Líquida, realizados em nanquim sobre papel no ano de 2020. As obras envolvem relações poéticas e conceituais com produções de mulheres artistas e escritoras que são referências para a autora, constituindo registros de encontros ficcionais. A série foi produzida a partir de questionamentos acerca da construção do pensamento misógino na história da filosofia ocidental, e os caminhos percorridos no processo de produção resultaram em uma poética que envolve o conceito de liquidez como potência criadora e a fabulação como procedimento de criação de uma narrativa em que a costura é realizada pelas linhas de tinta do desenho.

Palavras-chave: Arte contemporânea. Desenho. Fabulação. Mulheres artistas. Subjetividade.

\begin{abstract}
ABSTRACT: This work is a visual essay composed of eight drawings from a series named Liquid Stitching, made with ink on paper in the year 2020. The works stem from poetic and conceptual connections with works by female artists and writers that are references for the author, constituting records of fictional encounters. The production of this series was triggered by reflections about the construct of misogyny within the history of western philosophy, and the paths that were taken during the production process led to a poetic approch that involves the concept of liquidity as a creative power and fabulation as a creative procedure for a narrative where the stitching is done through the drawn ink lines.
\end{abstract}

Keywords: Contemporary art. Drawing. Fabulation. Women artists. Subjectivity.

1 Mestranda em Artes Visuais pela Universidade do Estado de Santa Catarina, na linha de Processos Artísticos Contemporâneos (2020-2022), sob orientação da Profá. Drạ. Sandra Maria Correia Favero. Pesquisa memória, fabulação e narrativas ficcionais. Lattes CV: http://lattes.cnpq.br/6532255119948873. Orcid: https://orcid. org/0000-0003-4615-5465. Email: luanda.deoliveira@gmail.com. O presente trabalho foi realizado com apoio da Coordenação de Aperfeiçoamento de Pessoal de Nível Superior - Brasil (CAPES) - Código de Financiamento 001. 


\section{Resumen}

Esta obra es un ensayo visual compuesto por ocho dibujos de una serie titulada Costura Líquida, realizados a tinta sobre papel en el año 2020. Las obras están conectadas a relaciones poéticas y conceptuales con las producciones de mujeres artistas y escritoras que son referencias para la autora, constituyendo registros de encuentros ficticios. La producción partió de reflexiones sobre la constitución del pensamiento misógino dentro de la historia de la filosofía occidental, y la trayectoria recorrida en el proceso de producción dieron como resultado una poética relacionada com el concepto de liquidez como poder creador y la fabulación como procedimiento para crear una narrativa donde la costura se realiza a través de las líneas de tinta del dibujo.

Palabras clave: Arte contemporáneo. Dibujo. Fabulación. Mujeres artistas. Subjetividad. 
Na série Costura Líquida apresento desenhos realizados a partir de exercícios de sensibilidade às obras de mulheres artistas e escritoras que integram meu corpo de referências, constituindo encontros ficcionais. A série teve início após meu contato com determinados discursos veiculados ao longo da história ocidental da filosofia como justificativas para a misoginia. Em relação ao pensamento europeu do século XVIII, Michèle Crampe-Casnabet aponta que o discurso dominante dos filósofos iluministas afirmava que as mulheres estariam presas a um tipo de imaginação infantil, sendo incapazes de utilizarem o pensamento abstrato para a construção de conhecimento.

Senhora do erro e da falsidade, a imaginação está marcada pelo selo da infância. Por excesso de imaginação pode ficar-se doente, enlouquecer ou morrer. É por isso que a fixação do espírito feminino no estádio imaginativo explica que ele continue a ser infantil, frágil e incontrolável. Um dos remédios indispensáveis mas sempre insuficiente para esta "loucura" latente no ser feminino é proibir- lhe a leitura dos romances, essas obras de ficção de que somente a solidez do espírito viril pode fazer uso. (CRAMPE-CASNABET, 1999, p. 387)

Uta Ranke-Heinemann (1996) aponta que Alberto Magno, teólogo do século XIII, afirmou que a mulher seria menos qualificada para o comportamento moral, por conter "mais líquido" em seu corpo que o homem. Portanto, como os líquidos se movem com facilidade, as mulheres seriam inconstantes e curiosas. Considero sintomático deste imaginário o uso da palavra "solidez" por Crampe-Casnabet, ao referir-se à qualidade masculina que, segundo os iluministas, permitiria um contato seguro com as obras de ficção.

A produção apresentada neste ensaio visual propõe uma ressignificação destes discursos e uma apropriação do direito à imaginação, através de uma poética da liquidez como potência criadora, prolífica e móvel, em oposição ao que seria uma solidez árida e estanque. Trata-se também de um exercício narrativo de uma história das artes produtora de subjetividade: partes do caderno de uma artista, onde são feitos enlaces entre outras mulheres de singularidades diversas.

Meu objetivo não é simplesmente realizar um registro de referências ou tentar reafirmar a evidente relevância das produções de determinadas artistas, mas sim dar materialidade a um certo modo de percorrer as páginas de outros tantos livros: com a fabulação como parte de uma metodologia de produção e pesquisa no campo das Artes Visuais. Segundo Mariana Rodrigues Pimentel, a fabulação "é uma operação de dobra da ficção, dobra através da qual a ficção re-encontra a vida, ou seja, a sua potência criadora de vida" (PIMENTEL, 2010, p. 12). Considero que uma das grandes potências da arte e da ficção seja a de apresentar impossibilidades que coloquem o possível em movimento, criando assim fluxos de vida que possam se infiltrar na re- 
alidade. Pergunto, então: e se Penélope e Ariadne ${ }^{2}$ escrevessem juntas seu próprio livro, costurando narrativas sobre mulheres artistas de tempos e lugares diversos? A partir desta impossibilidade, ou desta fabulação, componho micronarrativas através de desenhos e títulos, tomando emprestada de Penélope a habilidade para a costura, e de Ariadne a aptidão para percorrer labirintos.

Meu labirinto é um quarto de costura, onde forjo o trabalho com linhas de tinta, escutando muitas vozes através das paredes úmidas. Com a liquidez transformada em fio, revisito questões poéticas relacionadas aos atos de costurar e tecer, que perpassam as produções de artistas como Sônia Gomes, Louise Bourgeois e Cecilia Vicuña, e atravesso com linhas vermelhas os mares escritos por Emily Dickinson e a tinta fresca do autorretrato de Artemisia Gentileschi. Nesta série, a maleabilidade da linha aproxima-se da tripla significação da palavra "capilar", relativa tanto ao fio de cabelo quanto aos menores vasos sanguíneos, mas também à qualidade de movimentação dos líquidos denominada "capilaridade".

Em sua carta às mulheres escritoras do terceiro mundo, Gloria Anzaldúa clama: "Não deixem a tinta coagular em suas canetas" (ANZALDÚA, 2000, p. 235), conjugando a potência dos líquidos e a apropriação do direito à criação. Os encontros apresentados a seguir são infiltrações em páginas da história com a liquidez de uma subjetividade produzida através de movimentações capilares e fluxos em direções diversas. Mas são também alguns dos possíveis exercícios para impedir que minha tinta coagule.

2 De acordo com Kury (2009), na mitologia grega Penélope foi a esposa de Ulisses, conhecida pelo ardil de evitar um segundo casamento durante a longa ausência do marido, que fora lutar na guerra de Tróia. Ela teria prometido escolher um de seus pretendentes quando terminasse de tecer uma mortalha, a qual tecia durante o dia, mas secretamente desfazia o trabalho à noite. Já Ariadne teria entregado a Teseu o novelo de linha que lhe permitiu encontrar a saída do labirinto habitado pelo Minotauro. 


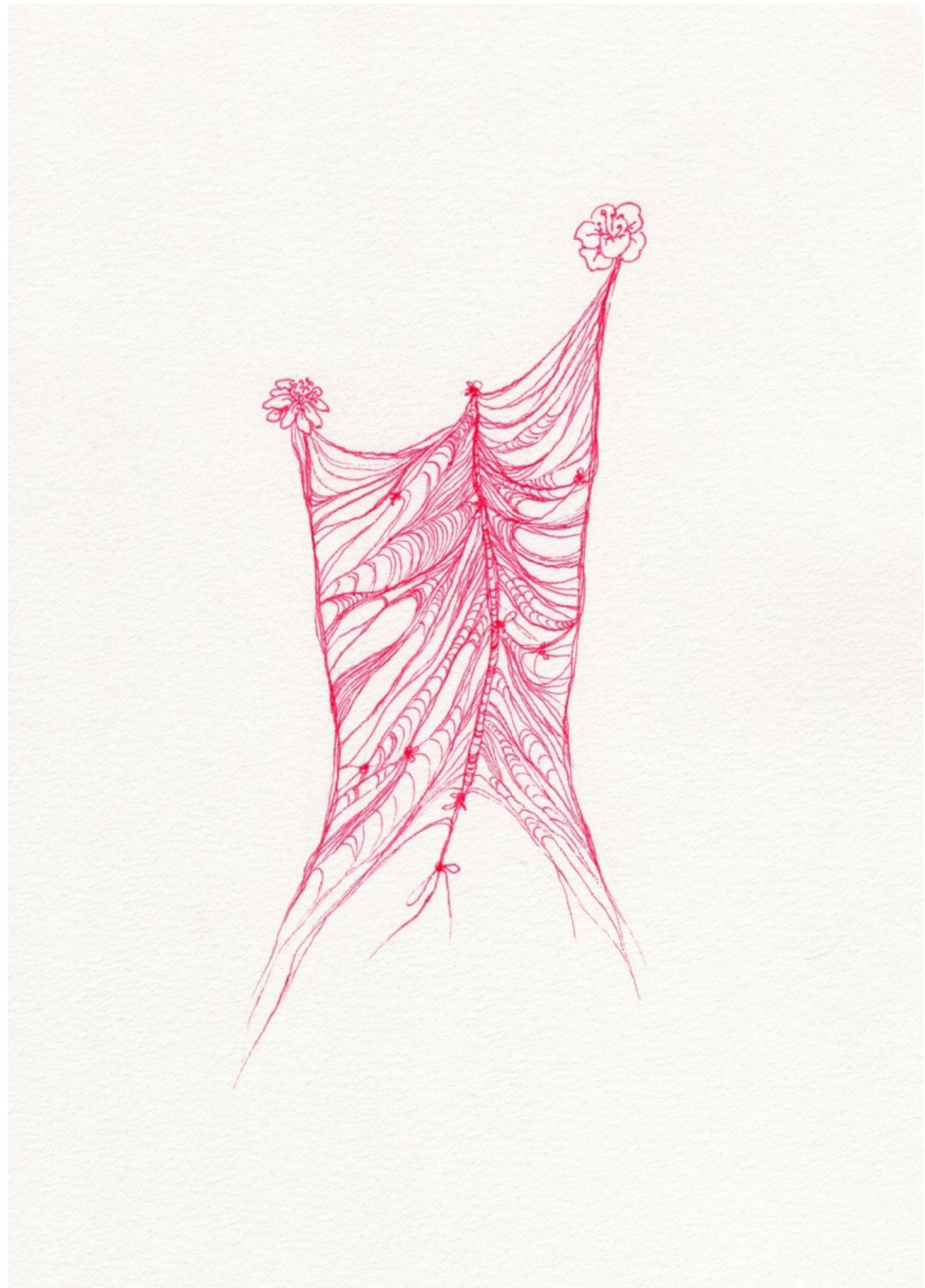

Figura 1. Luanda Ribeiro, Ariadne e Penélope escrevem um livro, 2020.

Nanquim sobre papel, $21 \times 15 \mathrm{~cm}$.

Fonte: Florianópolis, acervo da artista. 


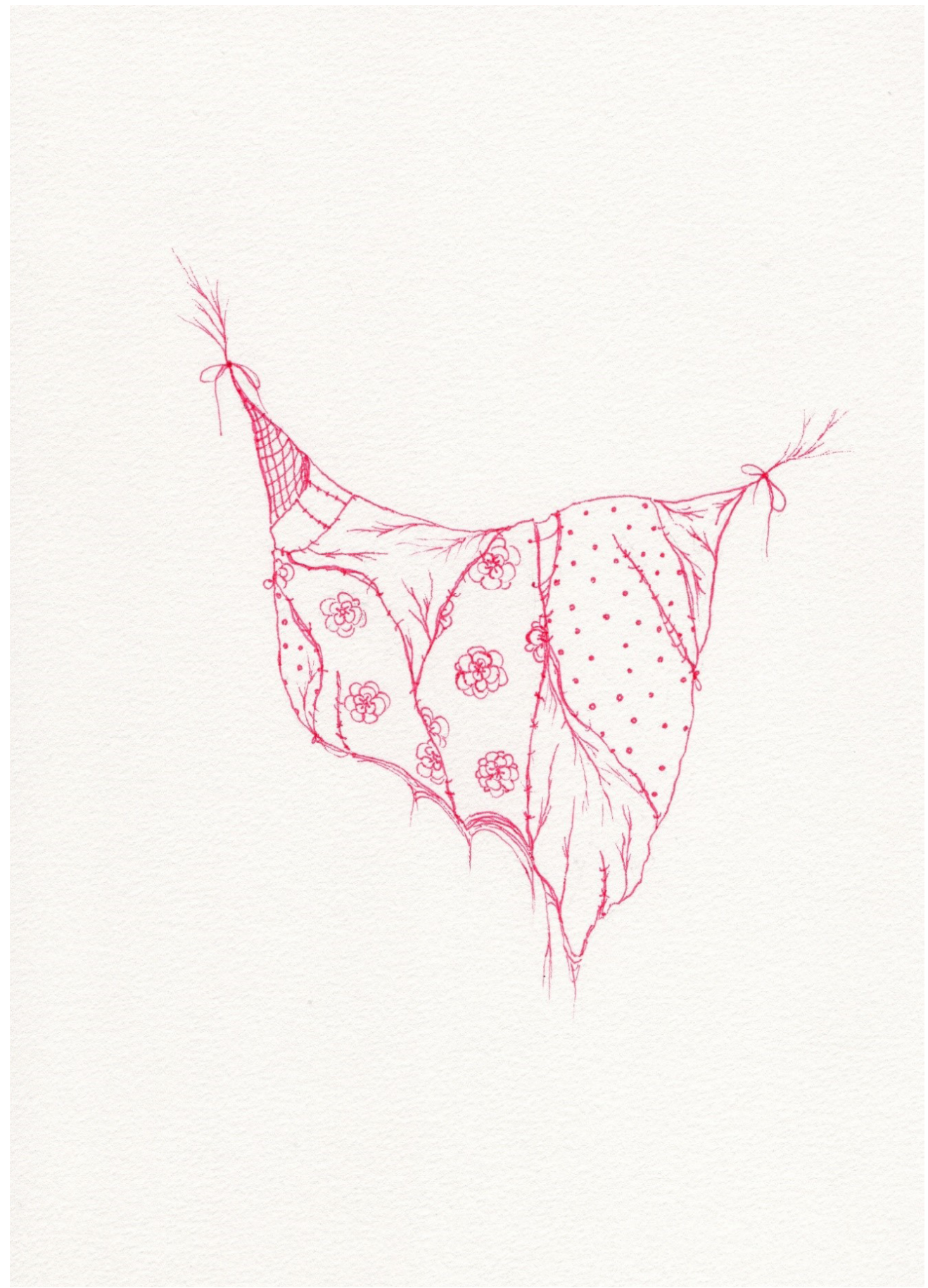

Figura 2. Luanda Ribeiro, No casulo de Sônia Gomes, 2020.

Nanquim sobre papel, 21x15 cm.

Fonte: Florianópolis, acervo da artista. 
Figura 3. Luanda Ribeiro, Enquanto Artemisia Gentileschi pinta seu autorretrato, 2020. Nanquim sobre papel, $21 \times 15 \mathrm{~cm}$.

Fonte: Florianópolis, acervo da artista. 
Figura 4. Luanda Ribeiro, Café com Lygia Clark, 2020.

Nanquim sobre papel, 21×15 cm.

Fonte: Florianópolis, acervo da artista. 


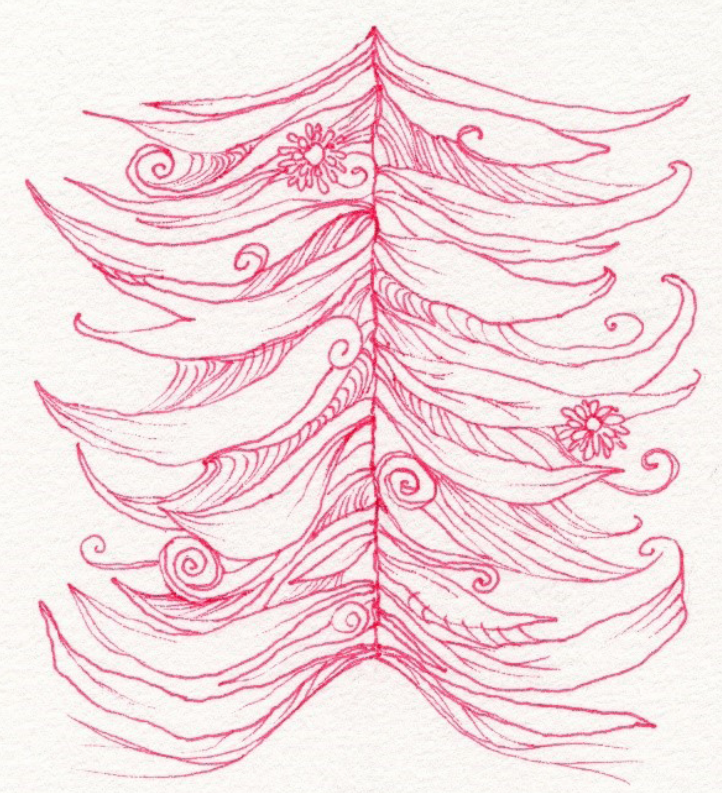

Figura 5. Luanda Ribeiro, Em mares de Emily Dickinson, 2020.

Nanquim sobre papel, 21x15 cm.

Fonte: Florianópolis, acervo da artista. 
Figura 6. Luanda Ribeiro, Sonhando o fio de sangue com Cecilia Vicuña, 2020. Nanquim sobre papel, $21 \times 15 \mathrm{~cm}$.

Fonte: Florianópolis, acervo da artista. 


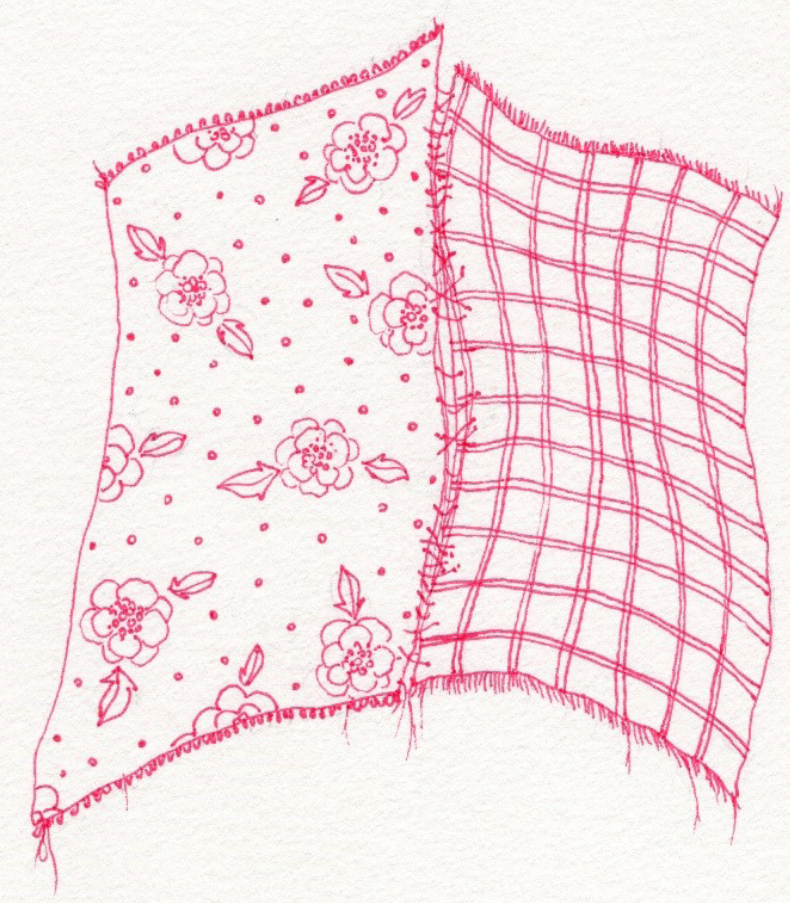

Figura 7. Luanda Ribeiro, Na casa de Louise Bourgeois e Eugénie Grandet, 2020.

Nanquim sobre papel, $21 \times 15 \mathrm{~cm}$.

Fonte: Florianópolis, acervo da artista. 


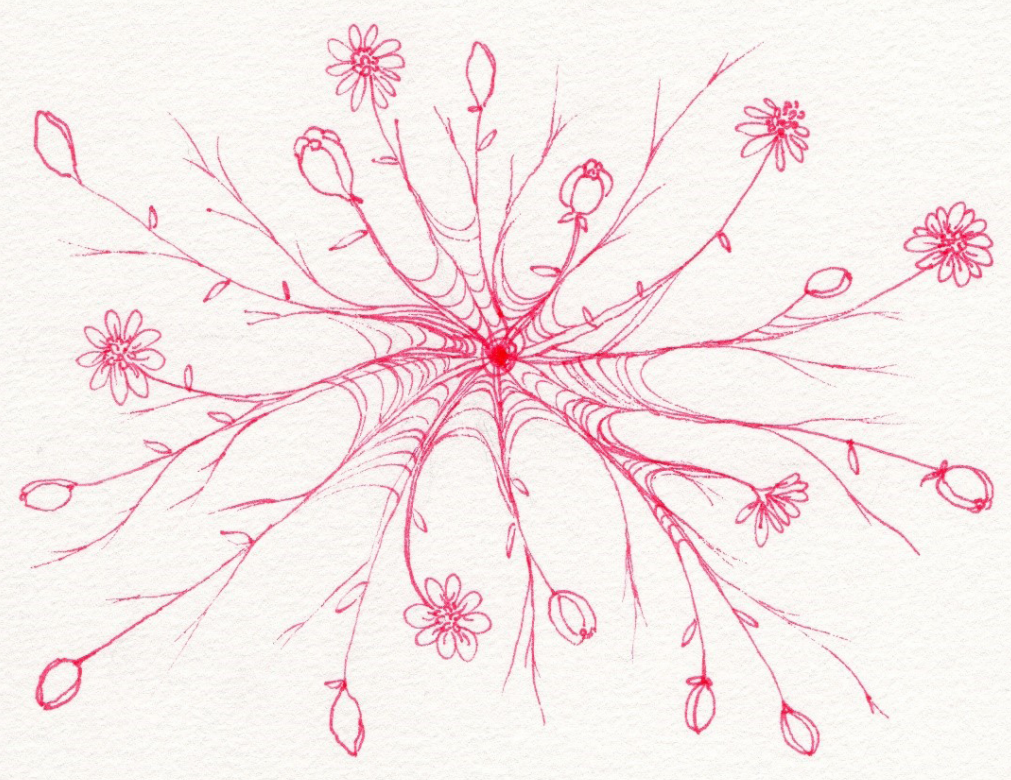

Figura 8. Luanda Ribeiro, Infiltrações da tinta de Gloria Anzaldúa, 2020.

Nanquim sobre papel, 21×15 cm.

Fonte: Florianópolis, acervo da artista. 


\section{Referências}

ANZALDÚA, Gloria. Falando em línguas: uma carta para as mulheres escritoras do terceiro mundo. Tradução de Édna de Marco. Revista Estudos Feministas. Florianópolis, v. 8, n. 1, p. 229-235, jan 2000. Disponível em: https://periodicos. ufsc.br/index.php/ref/article/view/9880 Acesso em: 28 jan. 2021.

CRAMPE-CASNABET, Michèle. A mulher no pensamento filosófico do século XVIII. In: DUBY, G.; PERROT, M. (Dirs). História das mulheres no ocidente: do Renascimento a Idade Moderna, v. 3. Porto, Portugal: Afrontamento, 1999.

KURY, Mário da Gama. Dicionário de mitologia grega e romana. 8. ed. Rio de Janeiro: Zahar, 2009.

PIMENTEL, Mariana Rodrigues. Fabulação: a memória do futuro. 2010. Tese (Doutorado em Letras) - Pontifícia Universidade Católica, Rio de Janeiro, 2010.

RANKE-HEINEMANN, Uta. Eunucos pelo reino de Deus: mulheres, sexualidade e a Igreja católica. Rio de Janeiro: Rosa dos Tempos, 1996.

Submetido em 27/02/2021

Aprovado em 03/04/2021 